\title{
A relação entre ortografia e fonologia na formação de interjeições
}

\author{
Natália Cristine Prado \\ Universidade Federal de Rondônia (UNIR), Porto Velho, Rondônia, Brasil \\ natalia.prado@unir.br \\ http://orcid.org/0000-0001-8947-4330
}

DOI: http://dx.doi.org/10.21165/el.v47i1.1920

\begin{abstract}
Resumo
O objetivo desta pesquisa é investigar a relação entre fonética/fonologia e a ortografia de interjeições encontradas em HQs. Para compor o corpus desta pesquisa, coletamos 92 interjeições de base onomatopaica/expressiva a partir dos gibis da "Turma da Mônica", da revista Turma da Mônica Jovem e, por fim, das tiras diárias publicadas no jornal Folha de São Paulo. As análises deste trabalho exploram primordialmente a relação entre ortografia e fonética/fonologia e foi possível observar que a escrita de algumas interjeições encontradas passa por um processo de estilização da grafia - muitas vezes com o intuito de trazer elementos prosódicos para o vocábulo, por exemplo, volume e duração. Com esta investigação, esperamos colaborar não apenas para a compreensão da linguagem dos quadrinhos, mas para uma compreensão mais global da fonética, da fonologia e da ortografia da língua portuguesa.
\end{abstract}

Palavras-chave: interjeição; ortografia; fonologia.

\section{The relation between spelling and phonology in the formation of interjections}

\begin{abstract}
This research aims to investigate a relation between phonetics / phonology and the spelling of interjections found in comic books. To compose the corpus of this research, 92 onomatopoeic / expressive interjections were collected from the "Turma da Mônica" [Monica and Friends] comic books, from the magazine Turma da Mônica Jovem [Monica Teen] and from the daily strips published in Folha de São Paulo newspaper. The analysis of this work mainly explores the relation between spelling and phonetics/phonology, so we could observe that the writing of the interjections found goes through a process of stylization of the spelling - often with the intention of bringing prosodic elements to the word, for example, volume and duration. With this research, we hope to collaborate not only for the comprehension of the comic books language, but also for a more global understanding of phonetics, phonology and the spelling of the Portuguese language.
\end{abstract}

Keywords: interjections; orthography; phonology.

\section{Introdução}

O objetivo deste estudo é investigar interjeições a partir de Histórias em Quadrinhos (doravante HQs) brasileiras publicadas de modo impresso no formato gibi, observando a relação entre fonética/fonologia e ortografia que se estabelece na escrita dessas palavras. A importância deste estudo reside no fato de que ainda são poucos os trabalhos da área de Linguística que se dedicam a observar, enquanto sistema, a linguagem verbal presente nos quadrinhos, já que, por muito tempo, as HQs não eram consideradas objetos de estudos acadêmicos. 
Vergueiro (2005, p. 17) explica que, na década de 1970, muitos estudiosos simplesmente não consideravam dignos de atenção os pesquisadores interessados por HQs e, "com isso, colocaram um ponto final no assunto, afirmando que as histórias em quadrinhos definitivamente não pertenciam ao meio acadêmico". Além disso, segundo Ramos (2012), já se considerou inaceitável levar os quadrinhos para a sala de aula.

Mesmo diante do atual interesse que os quadrinhos despertam e de sua inclusão nos Parâmetros Curriculares Nacionais (PCN), notamos, durante a pesquisa, que ainda são poucos os trabalhos que observam a linguagem verbal presente nesse material. Portanto, podemos dizer que, ainda hoje, não são muitos os estudos que realizam análises fonológicas, morfológicas, sintáticas ou lexicais do Português Brasileiro (doravante PB) a partir da linguagem dos quadrinhos ${ }^{1}$.

Assim, a importância desse estudo reside em compreender melhor as questões ortográficas, fonéticas e fonológicas dos quadrinhos, o que é o primeiro passo para caminhar em direção à compreensão global da linguagem desse hipergênero, que se mostra cada vez mais presente nas primeiras leituras das crianças, jovens e adultos, além de ser muito usado em livros didáticos de língua portuguesa.

Portanto, com essa pesquisa, esperamos colaborar com os estudos sobre a linguagem verbal presente nos quadrinhos brasileiros. Consequentemente, pretendemos contribuir para uma melhoria da compreensão dos fenômenos linguísticos dos quadrinhos, o que pode ajudar na prática de escrita e leitura de HQs em sala de aula.

\section{Fundamentação teórica}

Em primeiro lugar, é interessante observar que nosso objeto de estudos possui várias faces. O termo "quadrinhos" (ou mesmo "histórias em quadrinhos - HQs") faz referência a diferentes gêneros de textos, cada um com suas particularidades, por exemplo, cartuns, charges, tiras cômicas, tiras cômicas seriadas, graphic novels, mangás, entre outros. Por conta dessa característica, alguns estudiosos, como Mendonça (2002) e Ramos (2006, 2009, 2012), acreditam que os quadrinhos possam ser considerados como um hipergênero e não simplesmente um gênero textual.

De acordo com Maingueneau (2015, p. 130), “um hipergênero não é um gênero do discurso, mas uma formatação com restrições fracas que podem recobrir gêneros muito diferentes". É o caso do diálogo, do jornal, da carta, do diário etc. que, para ele, são modos de apresentação formal e de organização de enunciados, por isso restringem a enunciação de modo frouxo. Já outros hipergêneros, como o relatório ou a entrevista, conseguem ser mais restritivos, tendo em vista que um relatório policial, por exemplo, possui semelhanças enunciativas com outros tipos de relatórios. Para Ramos (2009), pensar nos quadrinhos como um hipergênero significa dizer que o termo "quadrinhos" é um rótulo que agrega diferentes gêneros, cada um com suas particularidades. De acordo com o autor, "um hipergênero anteciparia informações textuais ao leitor e ao produtor e funcionaria como um guarda-chuva para diferentes gêneros, todos autônomos, mas com

\footnotetext{
${ }^{1}$ Ramos (2006) afirma que há vários trabalhos sobre HQs pertencentes à área de Comunicação que enfocam as características da linguagem desses gêneros enquanto veículos de comunicação de massa. $\mathrm{O}$ estudioso acrescenta que as pesquisas pertencentes à área da Linguística são mais recentes, ou seja, se fortaleceram a partir da segunda metade da década de 90.
} 
características afins" (RAMOS, 2009, p. 366). Deste ponto de vista, podemos abrigar os diferentes modos de produção de quadrinhos nesse rótulo.

$\mathrm{O}$ uso das HQs na sala de aula de língua portuguesa tem rendido algumas discussões no meio acadêmico. Passos e Vieira (2014), por exemplo, observaram que as histórias em quadrinhos podem contribuir para uma leitura mais proficiente. Sabendo que as HQs despertam interesse em estudantes de todas as idades, pela associação da linguagem verbal e não verbal, as autoras analisaram algumas tirinhas e puderam concluir que os quadrinhos representam um importante recurso pedagógico para $o$ ensino de português.

Silva (2011) observou que as histórias em quadrinhos podem contribuir para a formação de leitores com senso crítico apurado. Ao analisar importantes super-heróis dos quadrinhos, como Superman e o Justiceiro, o autor constata as ideologias por trás dessas figuras e defende que esses quadrinhos podem colaborar para gerar importantes reflexões nas aulas de interpretação e escrita de textos, o que contribui para o aprimoramento da leitura crítica.

Já Silvério e Rezende (2014) observaram o valor pedagógico das HQs na formação do professor de língua portuguesa. As autoras entrevistaram dez professores, investigaram suas práticas docentes e constataram que eles reconhecem a importância dos quadrinhos como recurso pedagógico. Para as pesquisadoras,

[...] a exploração didática bem planejada pelo profissional docente no trabalho com a leitura por meio de linguagem verbal atrelada à linguagem não verbal presente no gênero HQs possibilita o uso desses materiais nas salas de aula, com vistas à formação do leitor competente, conforme é desejável e esperado. (SILVÉRIO; RESENDE, 2014, p. 231).

Há alguns estudos que observam a linguagem dos quadrinhos, como Eguti (2001), Passarelli (2004) e Ramos (2005), que ressaltam os aspectos da oralidade ali representada. De acordo com essas pesquisas, principalmente Eguti (2001), é possível perceber que os diversos tipos de quadrinhos são um terreno fértil para a representação da língua falada, bem como dos demais elementos que a constituem como gestos, voz e outros. Ramos (2016) afirma que esse hipergênero simula as várias características da modalidade oral da língua. Assim, os balões representam os turnos conversacionais e "o formato das letras e o contorno dos balões indicariam tom de voz mais elevado, mais baixo, a emoção sentida no momento da fala do personagem" (RAMOS, 2006, p. 1580).

Cagnin (2014[1975], p. 34), em um estudo clássico sobre quadrinhos, apontou os seguintes constituintes das HQs: dos quadrinhos;

Imagens ou figuras desenhadas e limitadas pelas linhas ou molduras

Texto, apresentado em forma de balão (e seus derivados) ou legenda (pouco usada atualmente) e em forma de onomatopeias, que podem ser em língua portuguesa ou em língua inglesa, que, segundo o autor, estão já "incorporadas por todos os idiomas rendidos pela avalanche dos comics americanos que invadiu o mundo após a criação dos syndicates, na década de 1930, a chamada época de ouro dos Quadrinhos" (CAGNIN, 2014[1975], p. 34). 
O autor chama a atenção para o fato de que existem ainda as HQs sem texto, que contêm apenas um título, chamadas de histórias mudas ou de sans parole. Para o autor, essas seriam as verdadeiras histórias em quadrinhos, pois não se valem de outro código que não o icônico para contar uma história, justificando ainda mais o título "Arte Sequencial", criado por Will Eisner. Com isso, o autor demonstra que o texto é um segundo elemento das HQs, que, portanto, não são dependentes dele para que existam.

Entretanto, constata-se a invariável presença da palavra na maioria das publicações de HQs. Cagnin (2014[1975], p. 138) observa que quase sempre é o texto que, em lugar de auxiliar as imagens, assume o papel principal nas histórias que, a princípio, seriam contadas por imagens. De acordo com ele, a linguagem articulada do código linguístico é suficiente para a comunicação e pode sustentar sozinha a função narrativa de uma HQ. Trabalhando juntamente, a linguagem desvenda o sentido denotativo de uma imagem e ajuda na interpretação de semas conotativos. Assim, imagem e palavra se acham em relação complementar, ambas fazem parte do sintagma superior da narração e a constroem.

As interjeições, ao lado das onomatopeias, aparecem com muita frequência em HQs, entretanto, como demonstra nossa pesquisa, o termo interjeição é omitido em algumas gramáticas. Nas gramáticas que tratam do assunto, normalmente a palavra interjeição aparece na parte de classes de palavras.

É o caso da Moderna Gramática Portuguesa (BECHARA, 2009) em que o termo aparece na parte de "classes de Palavras e categorias gramaticais". Segundo o gramático, a interjeição "é a expressão com que traduzimos os nossos estados emotivos" (BECHARA, 2009, p. 330). Para ele, essas expressões têm existência autônoma e podem ser consideradas verdadeiras orações, embora possam também estabelecer relações e formar unidades complexas. São expressões que acompanham um contorno melódico exclamativo, mas podem assumir papel de unidades interrogativasexclamativas e de outras unidades como vocativos e imperativos.

Bechara (2009, p. 331) classifica as interjeições em quatro tipos. O primeiro deles é representado por sons vocálicos que, na escrita, se apresentam de maneira convencional, como ah!, Oh! e hum. Para o autor, o $h$ no final pode marcar uma aspiração, alheia ao sistema do português. O segundo tipo é formado por palavras correntes na língua, como puxa!, bolas!, valha! (com contorno melódico exclamativo). Fazem parte do terceiro tipo de interjeições as palavras que procuram reproduzir ruídos de animais ou de objetos, ou de outra origem, como clic (clique) e pum!. Por fim, o quarto tipo de interjeição é composto de locuções interjetivas do tipo ai de mim! ou cruz credo!

A interjeição, para Cunha e Cintra (1985, p. 396), “é uma espécie de grito com que traduzimos de modo vivo nossas emoções". De acordo com os autores, a mesma reação emotiva pode ser expressa por mais de uma interjeição e, inversamente, uma só interjeição pode "corresponder a sentimentos variados e até opostos". Para eles, o valor de cada forma interjectiva depende fundamentalmente do contexto e da entoação. A classificação para interjeições proposta nesta gramática leva em consideração o sentimento que as interjeições denotam, assim, existem interjeições de alegria, como oba!, de dor, como ai!, de silêncio, como psiu! etc. Os gramáticos comentam também a existência de locuções interjectivas, como ai de mim! Para Cunha e Cintra (1985, p. 397), as interjeições, entendidas por eles como vocábulos-frases, não são 
consideradas uma classe de palavras, pois equivalem a "frases emocionais", já que traduzem sentimentos súbitos e espontâneos.

Bagno (2012, p. 425-426) concorda com os autores supracitados ao afirmar que:

A interjeição constitui um fenômeno de entoação, prosódico, e não uma categoria lexical plena como as demais - afinal, toda e qualquer palavra, de qualquer classe "Fogo!", "Chega!", "Demais!", "Gostosa!" -, ou mesmo uma sentença inteira pode constituir uma interjeição: "Valei-me, minha Nossa Senhora da Abadia!". A interjeição é, pois, "uma espécie de grito com que traduzimos de modo vivo nossas emoções", conforme bem definem os gramáticos Celso Cunha e Lindley Cintra (1985: 577).

Desse modo, para o autor, toda e qualquer palavra pode se transformar numa interjeição, por isso, a introdução de interjeições na lista de classes gramaticais seria considerada por ele como sendo excentricidade latina. Entretanto, para Cegalla (2009, p. 300), a interjeição pertence à classe das palavras invariáveis e é "uma palavra ou locução que exprime um estado emotivo". São vozes ou exclamações vivas que podem exprimir e registrar diferentes sentimentos e emoções, ou seja, é um recurso da linguagem afetiva ou emocional. Esta gramática também leva em conta o tipo de sentimento que as interjeições exprimem, assim, há interjeições de desagrado, como arre!, e de desejo, como tomara!, porém o autor lembra que a mesma interjeição pode registrar mais de um sentimento, segundo o tom de voz com que a proferimos. Ele também comenta a existência das interjeições imitativas, que seriam as palavras que "emitem ruídos e vozes" (CEGALLA, 2009, p. 301), como pum! e pof!.

O gramático comenta ainda a existência das locuções interjectivas que seriam expressões que valem por uma interjeição, como meu Deus! e ó de casa!. Para ele, as interjeições são como frases resumidas, assim, ué! teria valor de eu não esperava por essa!. O autor alerta que é importante distinguir entre as palavras que são exclusivamente interjeições como oh! e olá! e as palavras de outras classes gramaticais usadas eventualmente como interjeições, como viva! e cuidado!

Para Cagliari (2005, p. 1),

[...] na verdade, as interjeições não são, de fato, palavras da língua, mas ruídos que ocorrem juntamente com a fala, denotando atitudes do falante e que alguns escritores resolveram transpor para seus textos. Uma análise mais atenta da fala mostra que se trata de uma escolha que privilegia alguns casos e despreza outros. Nem todos os ruídos da fala têm interessado os escritores.

Assim, o autor não considera as interjeições de base onomatopaica como palavras da língua e chama a atenção para o fato de que as artes sequenciais em geral estão cheias de expressões que denotam ruídos.

Como é possível observar, podemos encontrar diferentes definições para o termo interjeição, algumas, por trazerem termos como "ruídos" ou "gritos", podem não ter boa aceitação. Entendemos que essas expressões aparecem, pois algumas categorias de interjeições foram formadas a partir de sons expressivos onomatopaicos, o que, na visão desses autores, caracterizaria itens não lexicais. O lugar dessas expressões na gramática também precisa ser avaliado com cuidado, pois, embora alguns autores defendam que 
essas interjeições não podem ser consideradas palavras da língua, outros pesquisadores já discutem a possibilidade de reconhecer esses tipos de interjeições como palavras.

Dingemanse, Torreira e Enfield (2013), por exemplo, apresentam uma reflexão interessante a partir da interjeição "huh?" ou, mais precisamente, de uma pequena interjeição de questionamento que, ao ser dita, tem a função de incitar no interlocutor um "conserto" daquilo que ele havia dito. Os autores trabalham com a possibilidade de este item ser considerado uma espécie de palavra universal. Os pesquisadores chegaram a essa conclusão, pois é uma interjeição encontrada nas línguas naturais em formas parecidas, algo similar ao "hum?" em português. Os autores acreditam que uma investigação acerca de palavras consideradas "banais", que costumam ser classificadas como ruídos ou itens não lexicais, pode gerar novas hipóteses sobre o surgimento e a motivação por trás desses "signos" linguísticos.

De modo geral, podemos considerar a interjeição como sendo um fenômeno de entoação com função expressiva e comunicativa e que, teoricamente, pode ocorrer com qualquer palavra ou enunciado, além de ocorrer também com itens de origem onomatopaica de classificação não consensual.

\section{Procedimentos metodológicos e análise dos dados}

Em busca das interjeições que interessam aos quadrinistas brasileiros, coletamos dados a partir de três fontes:

1. Quadrinhos infantis - para esta categoria, coletamos dados a partir das revistas "Turma da Mônica". Foram analisadas as edições das revistas Mônica, Magali, Cascão, Cebolinha e Chico Bento, do número 11 ao 16 e as edições da revista Turma da Mônica, de números 11, 12, 13, 14, 15 e 17 (todos publicados em 2016);

2. Quadrinhos infanto-juvenis - para observar os quadrinhos voltados ao público jovem, a escolhida foi a revista Turma da Mônica Jovem (TMJ), do número 92 ao 97 (todos publicados em 2016);

3. Quadrinhos adultos - os quadrinhos voltados ao público adulto usados nesta pesquisa foram encontrados no jornal Folha de São Paulo. Observamos, de março a agosto, as tiras diárias publicadas neste jornal e coletamos nossos dados a partir do trabalho de diferentes cartunistas brasileiros ${ }^{2}$, como Laerte, Caco Galhardo, Adão Iturrusgarai, Andre Dahmer, Fernando Gonsales e outros. Todos esses quadrinhos foram publicados no jornal em 2016.

Há um grande número de interjeições nos quadrinhos já que, de acordo com Cunha e Cintra (1985) e Bagno (2012), qualquer expressão ou palavra pode ser considerada uma interjeição, se considerarmos que a interjeição é um fenômeno de entoação, prosódico, e não uma categoria lexical plena como as demais. Seguindo esse ponto de vista, toda e qualquer palavra, ou mesmo uma sentença pode ser considerada uma interjeição. Por isso, como forma de delimitar esse estudo, selecionamos apenas as

\footnotetext{
${ }^{2}$ Para compor o corpus deste trabalho, escolhemos apenas um tipo de publicação por faixa etária. Embora os quadrinhos da "Turma da Mônica" tenham a autoria de Maurício de Souza, atualmente, todos os quadrinhos são escritos com a colaboração de diferentes roteiristas, mas seus nomes, muitas vezes, não são mencionados ao fim de cada história. Já os quadrinhos da Folha de São Paulo são assinados por diferentes quadrinistas de sucesso, desse modo, embora seja apenas um veículo, estamos mencionando os autores de cada quadrinho.
} 
interjeições de base onomatopaica/expressiva, ou seja, as interjeições consideradas, pelo dicionário Houaiss (2009), como sendo de origem onomatopaica ou como vocábulo expressivo. Para as interjeições que não estão dicionarizadas, coletamos as que consideramos que também podem se classificar dessa forma.

No Quadro 1, a seguir, apresentamos uma amostra das 92 interjeições encontradas nos quadrinhos observados. Esse quadro está organizado da seguinte forma: na primeira coluna estão os itens encontrados e suas variantes ortográficas, na segunda coluna estão as ocorrências seguindo a mesma notação do quadro anterior, na terceira coluna estão anotados o tipo de expressão ou intenção do item e na quarta coluna há a informação se o item está ou não dicionarizado (de acordo com o HOUAISS, 2009).

Quadro 1. Amostra de vocábulos coletados

\begin{tabular}{|c|c|c|c|}
\hline \multicolumn{4}{|c|}{ INTERJEIÇÕES } \\
\hline $\begin{array}{c}\text { Itens e } \\
\text { variantes } \\
\text { ortográficas }\end{array}$ & Ocorrências/publicação & $\begin{array}{l}\text { Expressão/ } \\
\text { intenção }\end{array}$ & $\begin{array}{c}\text { Dicionarizad } \\
\text { a }\end{array}$ \\
\hline 1) Aê & $\begin{array}{l}\text { 2/ MÔNICA 11, p. } 5 ; 8-\text { 1/MAGALI } \\
\text { 13, p. } 41-\text { 1/CEBOLINHA 16, p. } 63- \\
\text { 1/TMJ 97, p. } 66\end{array}$ & $\begin{array}{l}\text { Animação, } \\
\text { incentivo }\end{array}$ & Não \\
\hline 2) Afe & $\begin{array}{l}\text { 1/ MAGALI 11, p. } 9-\text { 2/ MÔNICA 11, } \\
\text { p. 10; } 21-\text { 2/CEBOLINHA 12, p. 7; } 9- \\
\text { 3/CASCÃO 14, p. 9; 10; } 19- \\
\text { 1/CASCÃO 15, p. } 61-\text { 1/CASCÃO 16, } \\
\text { p. } 4 \text { - 2/TMJ 93, p. 49; 61 - 2/TMJ 94, } \\
\text { p. 12; 29; } 59-\text { 2/TMJ 95, p. 16; } 81- \\
\text { 3/TMJ 97, p. 44; 52; } 112\end{array}$ & Impaciência & Não \\
\hline 3) Ahã & $\begin{array}{l}\text { 1/CEBOLINHA 15, p. } 21 \text { - 1/MAGALI } \\
\text { 16, p. } 10\end{array}$ & Concordância & Não \\
\hline 4) Aham & $\begin{array}{l}\text { 1/MÔNICA 14, p. } 33 \text {-1/MAGALI 15, } \\
\text { p. } 33 \text { - 1/TURMA DA MÔNICA 15, } \\
\text { p. } 32 \text {-1/MAGALI 16, p. } 27\end{array}$ & Concordância & Não \\
\hline 5) Ahn & 1/CASCÃO 16, p. 63 - 1/TMJ 96, p. 87 & $\begin{array}{l}\text { Dúvida; } \\
\text { admiração }\end{array}$ & Não \\
\hline 6) Aí & 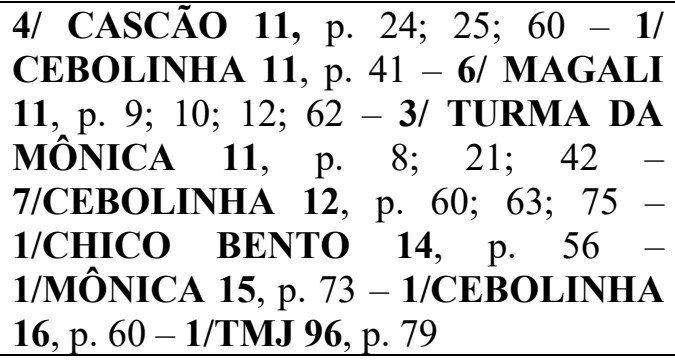 & $\begin{array}{l}\text { Sentido } \\
\text { brincalhão; } \\
\text { aprovação; } \\
\text { incentivo }\end{array}$ & Sim \\
\hline 7) Arrá & 1/FERNANDO GONSALES, 07/08 & Surpresa & Não \\
\hline 8) Arre & $\begin{array}{l}\text { 1/CHICO BENTO 14, p. } 54 \text { - 1/CHICO } \\
\text { BENTO 16, p. } 13-\text { 1/CACO } \\
\text { GALHARDO, } 14 / 04\end{array}$ & $\begin{array}{l}\text { Raiva; } \\
\text { preocupação }\end{array}$ & Sim \\
\hline 9) Irki & 1/CACO GALHARDO, 06/04 & Nojo & Não \\
\hline 10) Irra & 1/ TURMA DA MÔNICA 11, p. 15 & Animação & Sim \\
\hline 11) Iuhuuuu & $\begin{array}{l}\text { 1/MÔNICA 12, p. } 40 \text { - 1/CEBOLINHA } \\
\text { 15, p. } 19 \text {-1/MÔNICA 16, p. } 8\end{array}$ & Animação & Não \\
\hline
\end{tabular}




\begin{tabular}{|c|c|c|c|}
\hline 12) Nham & $\begin{array}{l}\text { 1/TURMA DA MÔNICA 11, p. } 22- \\
\text { 10/MAGALI 14, p. 4; 5; 10; } 11 ; 13 ; 14 ; \\
\text { 15; } 17 \text { - 1/CEBOLINHA 15, p. 56 - } \\
\text { 1/MAGALI 15, p. } 28 \text { - 2/CEBOLINHA } \\
\text { 16, p. } 10 \text { - 3/MAGALI 16, p. } 19 ; 60\end{array}$ & Fome & Não \\
\hline 13) Nhé & 1/TMJ 96, p. 39 - 1/TMJ 97, p. 25 & Negativa & Não \\
\hline 14) Ó & $\begin{array}{l}\text { 1/ TURMA DA MÔNICA 11, p. } 15- \\
\text { 1/CEBOLINHA 13, p. } 75 \text { - 1/MAGALI } \\
\text { 16, p. } 4 \text { - 2/LAERTE, 09/03; 10/03 - } \\
\text { 1/ALLAN SIEBER, } 19 / 03\end{array}$ & $\begin{array}{l}\text { Chamamento; } \\
\text { interpelação }\end{array}$ & Sim \\
\hline 15) Tsc & $\begin{array}{l}\text { 2/ TURMA DA MÔNICA 11, p. } 65- \\
\text { 2/CASCÃO 15, p. } 38 \text { - 4/CEBOLINHA } \\
\text { 15, p. } 12-\text {-3/TURMA DA MÔNICA 15, } \\
\text { p. } 27-2 / \text { TMJ 95, p. } 70\end{array}$ & Reprovação & Não \\
\hline 16) Uou & 1/ MAGALI 11, p. 56 & Animação & Não \\
\hline 17) Upa & $\begin{array}{l}\text { 5/CEBOLINHA 13, p. } 48 ; 49- \\
\text { 3/MAGALI 14, p. } 12 ; 18-\text { 3/MÔNICA } \\
\text { 16, p. } 24 ; 25\end{array}$ & $\begin{array}{l}\text { Incentivo; } \\
\text { encorajamento }\end{array}$ & Sim \\
\hline 18) Ups & $\begin{array}{l}\text { 1/MAGALI 12, p. } 16 \text { - 2/MÔNICA 14, } \\
\text { p. } 18 ; 24\end{array}$ & $\begin{array}{l}\text { Espanto; } \\
\text { surpresa }\end{array}$ & Não \\
\hline 19) Xi (xiii) & 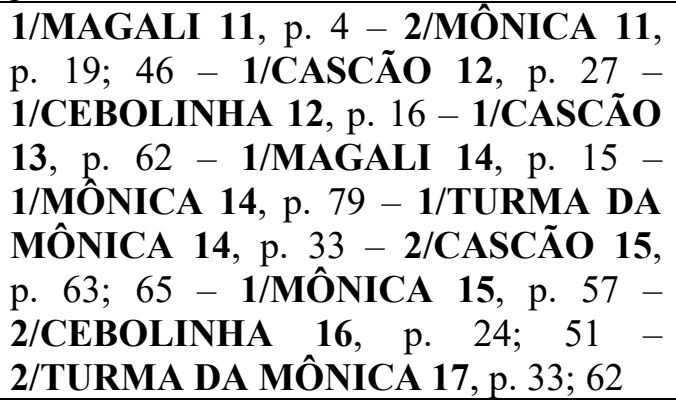 & $\begin{array}{l}\text { Espanto; } \\
\text { desagrado }\end{array}$ & Sim \\
\hline 20) Xô & $\begin{array}{l}\text { 2/CEBOLINHA } 12, \text { p. } 19 ; 56- \\
\text { 2/MAGALI 12, p. } 4 ; 5 \text { - 1/CHICO } \\
\text { BENTO 16, p. } 59-\text {-1/MAGALI 16, p. } 32\end{array}$ & Para enxotar & Sim \\
\hline 21) Yay & 2/TMJ 95, p. 35; 44 & Empolgação & Não \\
\hline
\end{tabular}

Após a coleta das interjeições de base onomatopaica/expressiva, passamos a analisar a relação entre fonologia e (orto)grafia na escrita desses vocábulos.

Em nossa análise, quando observamos os processos de formação dessas palavras e sua grafia, a principal questão que surgiu foi: como representar uma palavra que, muitas vezes, não tem ortografia definida, ou seja, palavras que não se encontram dicionarizadas. Diante disso e da necessidade de expressividade que as HQs apresentam, os quadrinistas acabam criando novos vocábulos e, muitas vezes, estilizando sua grafia.

Acreditamos que, a partir da observação de diversas interjeições (e também de onomatopeias) presentes nos quadrinhos, é possível observar as tendências de escrita desses vocábulos, que seguem, muitas vezes, uma grafia estilizada, ou seja, uma grafia diferente da ortografia oficial do PB (PRADO, 2014). A estilização gráfica não é exclusiva dessas palavras e pode aparecer também em nomes próprios, como antropônimos (MASSINI-CAGLIARI, 2010, 2011a,b, 2013; SOUZA, 2011 e MACEDO, 2015), como Mariah, Sarah e Kharla, e nomes comerciais (PRADO, 2014), como Autocenter Skinão e Ki-Bom, além de aparecer também em hipocorísticos 
(MACEDO, 2015), como Titiny, hipocorístico de Valentine, e na linguagem da internet, em bate-papos, redes sociais e blogs.

Cagliari (1993, p. 616), que também analisou interjeições e onomatopeias de diversos quadrinhos, acredita que a escrita dessas palavras "apresenta questões interessantes não só graficamente, como também para a ortografia e até para a gramática de uma língua”. Nas figuras 1 e 2, abaixo, vemos exemplos de interjeições em uso nos quadrinhos pesquisados.

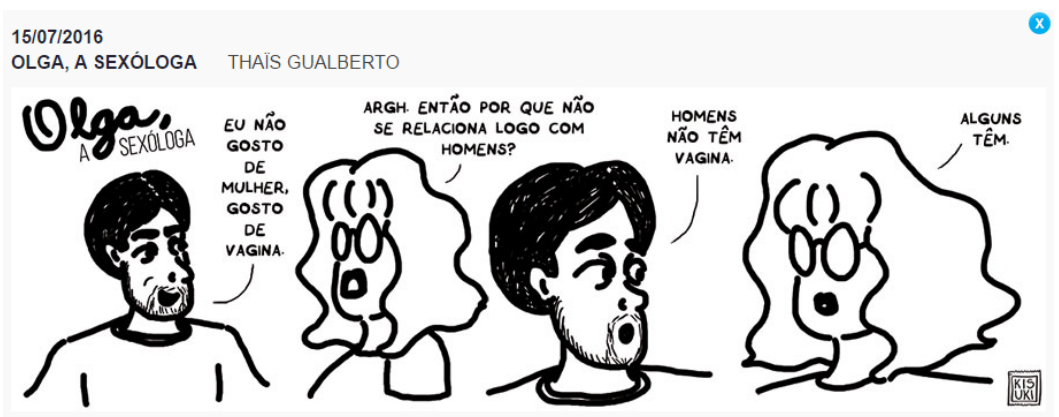

Figura 1. Exemplo de uso da interjeição de nojo/aborrecimento "argh"

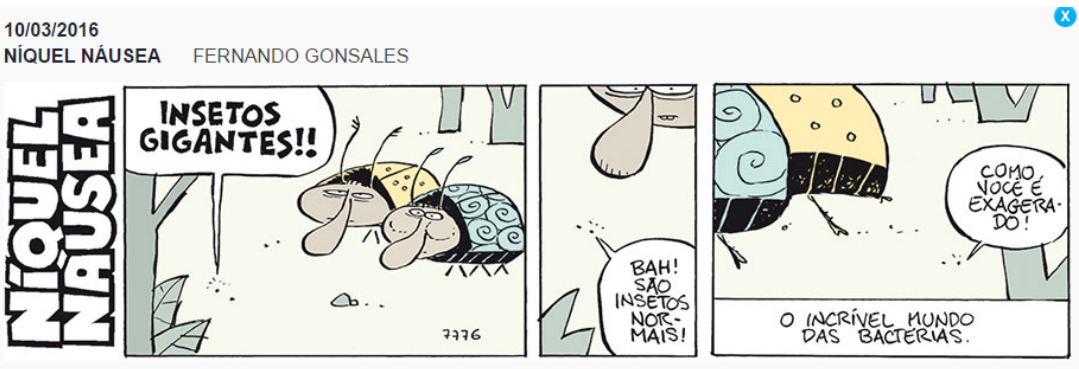

Figura 2. Exemplo de uso da interjeição de admiração/surpresa "bah"

A interjeição "argh", presente na Figura 1, é um exemplo de interjeição muito comum em HQs, mas que não se encontra dicionarizada, já a interjeição "bah", presente na Figura 2, encontra-se registrada no dicionário Houaiss (2009). Podemos dizer que a interjeição "argh" expressa nojo/aborrecimento e que "bah" expressa admiração/surpresa com base nos contextos de uso. Uma mesma interjeição pode expressar diferentes emoções, dependendo do contexto.

Observamos que, algumas vezes, esses vocábulos não seguem as convenções ortográficas do $\mathrm{PB}$, por trazerem letras multiplicadas, por exemplo. Em alguns momentos, notamos que a estilização ortográfica dessas palavras ocorre com o intuito de trazer elementos prosódicos para o vocábulo, por exemplo, volume e duração ${ }^{3}$, como

\footnotetext{
${ }^{3}$ Além da grafia das palavras, o balão de fala, por ser o elemento que mais caracteriza e dá dinamicidade à leitura dos quadrinhos, também pode carregar elementos prosódicos e expressar emoções das personagens: "na sua forma bem comportada, indica a fala coloquial de seus personagens. No entanto, quando estes mudam de humor, expressando emoções diversas (surpresa, ódio, alegria, medo), os balões acompanham tipologicamente, participando também da imagem. As formas são muitas e bastante variadas. Partindo-se do balão-fala, podemos encontrar o balão-pensamento, balão-berro, balão-cochilo, balão-trêmulo (medo), balão-transmissão (para transmitir sons de aparelhos elétricos ou eletrônicos), balão-desprezo, balão-uníssono (mostrando a fala única de diversos personagens), balão mudo e dezenas de informações diversas. Esses tipos e formas vão depender sempre da situação que se quer criar, ocasionando, assim, ótimos efeitos visuais e comunicativos” (LUYTEN, 1985, p. 12-13).
} 
podemos observar na interjeição de dor "ai" que aparece no quadrinho abaixo (Figura $3)$ :

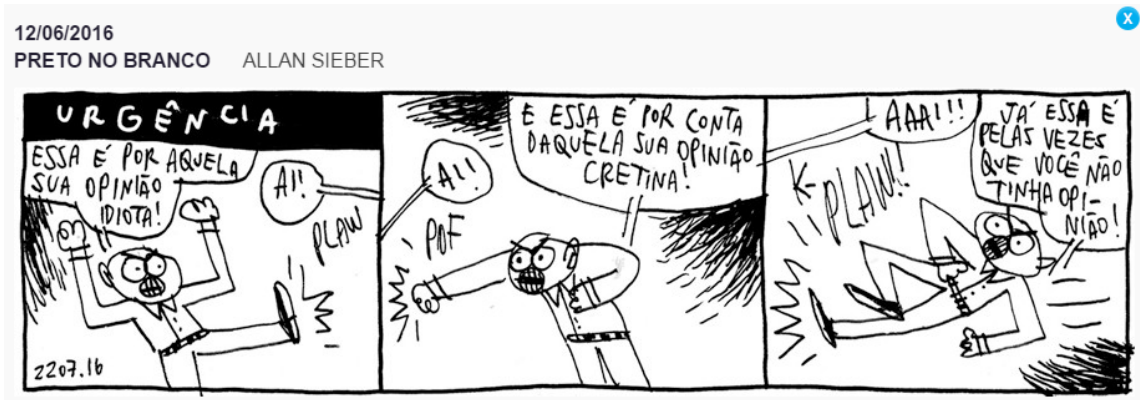

Figura 3. Exemplo de uso da interjeição de dor "ai"

Assim como acontece em outras palavras nos quadrinhos, a interjeição "ai" aparece com repetição de letras no terceiro quadrinho ("aaai"), o que pode indicar uma maior duração da vogal, marcando a intensidade expressiva dessa interjeição. Sobre a repetição de vogais nas interjeições coletadas, foi possível observar a repetição de muitos sons vocálicos. Além da repetição de "a" ou "á", representando [a] em "aaai" e "uááá", observamos a repetição de "ô", representando [o] em "aiôôô", "ê", representando [e] em "êêêêe"; "e" representando $[\varepsilon]$ "eeeh"; "o" representando [o] em "ooohh"; "i", representando [i] em "aaaiiii" e "u", representando [u] em "iuhuuu" e "u" seguido de consoante nasal, representando [u)] em "huuum". Dentre as 92 interjeições encontradas, 16 aparecem com variações de grafia em que há repetições de vogais.

A partir dos dados, trabalhamos com a hipótese de que todos os sons vocálicos, orais e nasais tendem a aparecer repetidos quando estão em sílabas tônicas ou em monossílabos tônicos.

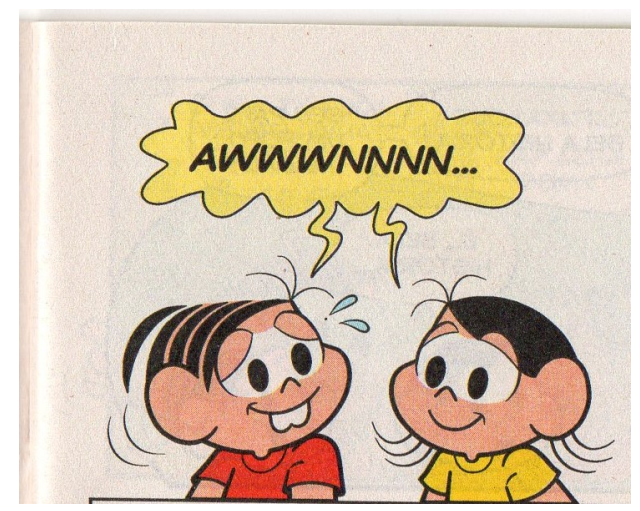

Figura 4. Exemplo de uso da interjeição de admiração “awn” (Magali, 2016, n” 16, p. 17)

No caso da interjeição "awwwnnn", podemos observar a repetição das consoantes "w" e "n" que, juntas, têm valor de [u)]. Assim, as nasais multiplicadas (ou não), nessa posição pós-vocálica, marcariam a nasalização da vogal. Encontra-se duplicada também a consoante nasal "m" como em "uhumm", que também podemos interpretar como prolongamento da vogal nasal $[\mathrm{u})]$.

No caso de "awwwnnn", acreditamos que há a influência do inglês e da escrita da internet, sobretudo das redes sociais, e observamos o uso de "w" com valor de "u", o que ocorre na ortografia oficial em casos particulares como palavras estrangeiras e 
derivadas, siglas e símbolos e nomes próprios (AZEREDO, 2012). Com relação à repetição de outras consoantes, além das nasais mencionadas, encontramos no corpus a repetição de "h", "r", "f", "s".

O uso do "h" final em interjeições aparece previsto pela ortografia oficial, além disso, há menção ao fato do "h" ser usado por "adoção convencional" em palavras como "hum!” (AZEREDO, 2012, p. 70-71), embora a afirmação seja um pouco vaga, pode-se dizer que há uma previsão para o uso do "h" em situações estilísticas. Observamos em nossos dados que o "h" multiplicado aparece após vogais em final de sílaba tônica e, mais frequentemente, de palavra; ele pode assumir o valor que o acento agudo desempenha na ortografia oficial, juntando-se, por exemplo, ao "e" e "o" para marcar os sons vocálicos médio-baixos $[\varepsilon]$ e $[\circ]$.

Esse tipo de uso do "h", que pode aparecer multiplicado ou não, também ocorre na escrita da internet, em ocorrências como "neh" e "kual eh" (que significam "não é" e "qual é", respectivamente) e escritas informais em geral, momentos em que não há uma preocupação com a norma ou há intenção de fugir propositalmente das convenções oficiais para conseguir novos efeitos de sentido. Este uso é tão popular em redes sociais e outros meios de comunicação pela internet que podemos considerá-lo uma espécie de convenção desse tipo de escrita, estabelecida pelos hábitos dos usuários.

$\mathrm{O}$ "h" nesses e em outros casos pode ainda ter papel de marcar a leve aspiração que ocorre após interjeições como "ah" e "oh". Essa letra também pode ser interpretada como zero fonético, em interjeições como "ahn" e como r-forte em "ahá", contextos em que não apareceram multiplicadas em nosso corpus.

O "r" aparece repetido em interjeições como "grrrr", sequência de consoantes ("gr") que, tomando como base o molde silábico do português, é válida como onset, mas que, sozinha, não poderia ser considerada uma sílaba do português completa, pois falta uma vogal. Essa letra, a princípio, deveria representar o prolongamento de uma vibrante (nessa configuração de onset, haveria um tepe). Mas, por ser uma sílaba que foge ao padrão do PB, é possível considerar outros valores de sons do " $r$ " que possam ser prolongados mais facilmente como $[\mathrm{h}],[\mathrm{x}]$ ou $[\Lambda]$, sons que podem ocorrer na oralidade com a intenção de demonstrar irritação e raiva.

As fricativas "f" e "s" aparecem multiplicadas em interjeições como "pssssiu" e "uff", representando, respectivamente, os sons [s] e [f]. Essas letras multiplicadas simbolizam uma maior intensidade desses sons fricativos que, eventualmente, podem ser usados individualmente na oralidade para chamar a atenção ou para expressar aborrecimento. No total, 13 interjeições apresentaram consoantes multiplicadas.

Ao analisar aspectos comuns às consoantes multiplicadas, podemos observar que há uma tendência em privilegiar os sons que tenham o traço [+ contínuo], ou seja, sons que são produzidos sem bloqueio total à passagem de ar pela cavidade oral, como as fricativas. Seria o caso de "s" com valor de $[\mathrm{s}]$, " $\mathrm{f}$ " com valor de [f] e "r" com valor de $[\mathrm{h}]$ e $[\mathrm{x}]$, por exemplo.

Como dito, observamos no corpus algumas interjeições ortograficamente formadas sem vogais, como "shhh" (Figura 5), que expressa um pedido de silêncio. Esse tipo de vocábulo desafia o padrão silábico e ortográfico do $\mathrm{PB}$, que não permite sílabas sem vogais (COLLISCHONN, 2005[1996], p. 120), o que abre a possibilidade para que possa ser interpretado apenas como um ruído expressivo emitido por pessoas, 
indicativo de seu humor ou de suas intenções, e não exatamente como uma palavra da língua. Encontramos apenas 6 interjeições formadas sem vogais.

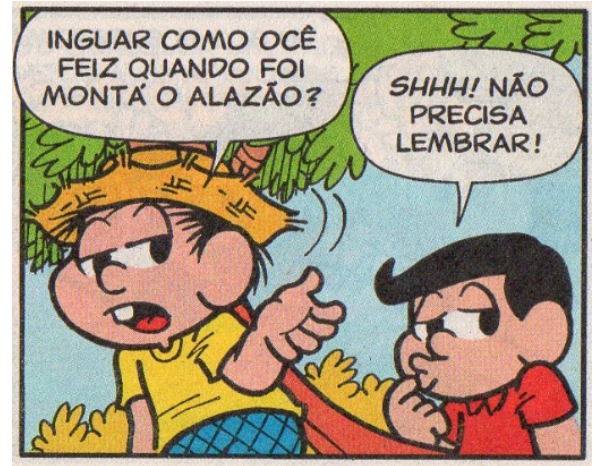

Figura 5. Exemplo de uso da interjeição de silêncio "shhh" (Chico Bento, 2016, nº 16, p. 5)

Importante ressaltar que Collischonn (2005[1996]) acredita que, em língua portuguesa, determinados segmentos e sequências de segmentos não são permitidas ou ocorrem apenas em situações pontuais. Em posição inicial de palavra, por exemplo, em $\mathrm{PB}$ não ocorre $/ \mathrm{n} / \mathrm{e} / \lambda /$, de modo que só encontramos estes segmentos nesta posição em palavras emprestadas de outras línguas ${ }^{4}$, por exemplo, lhama e nhoque. Como se observa, o uso desses sons em início de palavra fica restrito a alguns poucos casos em PB. É interessante observar que foi possível encontrar/n/ no início da interjeição "nhé", que expressa negação ou indiferença, como podemos ver na Figura 6. Assim, vemos que o uso restrito desses segmentos em posição inicial de palavras também se estende às interjeições e outras onomatopeias, mas continua sendo raro, pois só encontramos duas interjeições iniciadas em $/ \mathrm{n} /$.

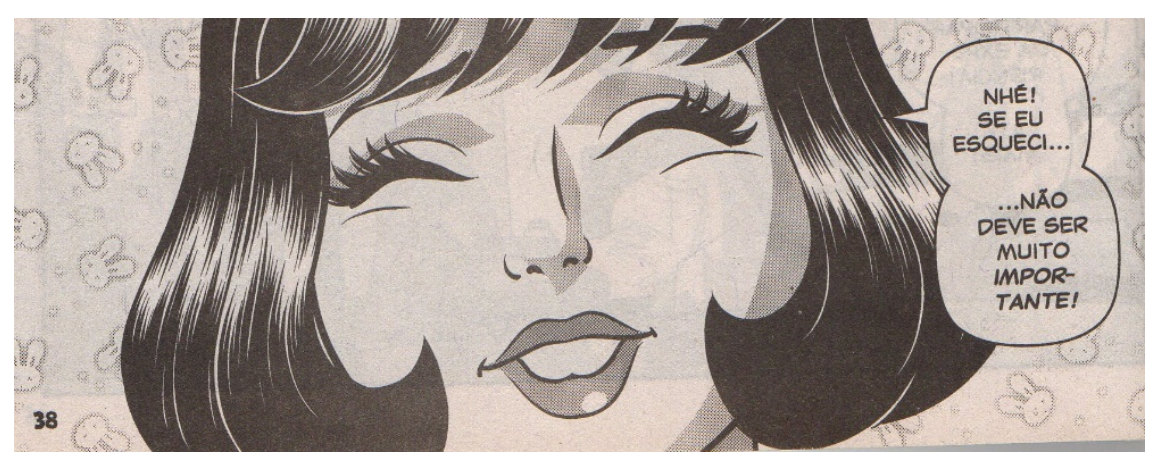

Figura 6. Exemplo de uso da interjeição de negação/indiferença "nhé" (Turma da Mônica Jovem, 2016, n⿳0 96, p. 38)

Como exposto, conseguimos coletar 92 interjeições de base onomatopaica, de modo que foi possível perceber que há uma grande riqueza lexical nos quadrinhos usados para a composição do nosso corpus.

\footnotetext{
${ }^{4}$ Em nossas leituras, também nos deparamos com a palavra lhufas, que, segundo o dicionário Houaiss (2009), é um pronome indefinido, que significa "coisa nenhuma", mas é considerada uma redução da palavra bulhufas.
} 


\section{Considerações finais}

As HQs são um material interessante para pesquisas linguísticas. Presentemente, observa-se que as publicações de quadrinhos, por destinarem-se a um público consumidor muito amplo, representam um índice expressivo da cultura de massa e merecem atenção.

Assim, acreditamos que a grafia de interjeições e outros casos de estilização de escrita em HQs também pode receber influência da linguagem da internet, em que é permitida uma escrita mais livre, cheia de abreviações e estilizações ortográficas. Por serem os quadrinhos uma fonte escrita que entra em contato com alunos em escolas, estudar os processos de estilização da sua grafia pode render reflexões importantes também sobre o papel desses materiais em sala de aula, até mesmo no estudo das normas ortográficas oficiais do português no Brasil.

Embora a ortografia do PB seja regida por regras (bases) e pelo VOLP (Vocabulário Ortográfico da Língua Portuguesa - versão Academia Brasileira de Letras), os cartunistas podem, conscientemente, optar por não seguir algumas regras, de modo que a escrita dos quadrinhos consiga traduzir a expressividade que esses autores desejam.

Durante o levantamento bibliográfico para a escrita deste trabalho, observamos que o estudo das interjeições acaba sendo excluído de algumas gramáticas e, com exceção de Cagliari (1993), nenhum dos pesquisadores consultados até o momento observou a escrita dessas palavras do ponto de vista fonético/fonológico e ortográfico, tomando como base o PB. Desse modo, é necessário que mais estudos sejam feitos para melhor caracterizar essas palavras a partir deste viés.

O fato de algumas interjeições de base onomatopaica serem escritas sem vogais, com a possibilidade de serem emitidas assim, faz com que possamos considerar a hipótese de que esses itens interjectivos estejam às margens do sistema do $\mathrm{PB}$, tendo em vista que esse idioma não permite sílabas sem vogais.

A hipótese levantada por Dingemanse, Torreira e Enfield (2013) de que algumas interjeições possam ser consideradas palavras universais também merece investigação e, para isso, seria necessário comparar interjeições em diversas línguas, o que ultrapassa nosso escopo de trabalho, que se interessa apenas por observar as interjeições em relação ao sistema fonético/fonológico e ortográfico do PB.

Por fim, com este artigo, esperamos colaborar para a compreensão da relação entre a ortografia e a fonologia do PB nas interjeições dos quadrinhos nacionais.

\section{REFERÊNCIAS}

AZEREDO, J. C. Escrevendo pela nova ortografia: como usar as regras do novo acordo ortográfico da língua portuguesa. São Paulo: Publifolha, 2012.

BAGNO, M. Gramática pedagógica do português brasileiro. São Paulo: Parábola Editorial, 2012.

BECHARA, E. Moderna gramática portuguesa. Rio de Janeiro: Editora Nova Fronteira, 2009. 
CAGLIARI, L. C. A escrita do barulho. Estudos Linguisticos - Anais de seminários do GEL, São Paulo, Instituição Moura Lacerda, v. 22, p. 615-622, 1993.

CAGNIN, A. L. Os quadrinhos: um estudo abrangente da arte sequencial: linguagem e semiótica. São Paulo: Criativo, 2014.

CEGAllA, D. P. Novíssima gramática da língua portuguesa. 48. ed. São Paulo: Editora Companhia Nacional, 2009.

CHICO BENTO. São Paulo: Panini Comics, n. 11, março 2016.

COLLISCHONN, G. A sílaba em português. In: BISOL, L. (Org.). Introdução a estudos de fonologia do português brasileiro. 4. ed. Porto Alegre: EDIPURCS, 2005[1996]. p. 101-133.

DINGEMANSE, M.; TORREIRA, F.; ENFIELD, N. J. Is “Huh?” a Universal Word? Conversational Infrastructure and the Convergent Evolution of Linguistic Items. PLoS ONE, 8(11): e78273, 2013. Disponível em: $<$ https://doi.org/10.1371/journal.pone.0078273 > . Acesso em: 08 mar. 2018.

EGUTI, C. A. A representatividade da oralidade nas histórias em quadrinhos. 2001. 198 f. Dissertação (Mestrado em Filologia e Língua Portuguesa) - Faculdade de Filosofia e Língua Portuguesa, Universidade de São Paulo, São Paulo, 2001.

LUYTEN, S. M. B. O que é histórias em quadrinhos. São Paulo: Editora Brasiliense, 1985.

MACEDO, N. Z. Análise fonológica de nomes próprios de origem estrangeira e novas criações em Português Brasileiro. 2015. 171 f. Dissertação (Mestrado em Linguística e Língua Portuguesa) - Faculdade de Ciências e Letras, Universidade Estadual Paulista "Júlio de Mesquita Filho", Araraquara, 2015.

MAINGUENEAU, D. Discurso e análise do discurso. São Paulo: Contexto: 2015.

MASSINI-CAGLIARI, G. Changing Attitudes: Ways of Phonologically Adapting Proper Names in Archaic Brazilian and European Portuguese. In: KOLOKONTE, M.; JANKE, V. (Org.). Interfaces in Language 3. v. único. Newcastle upon Tyne: Cambridge Scholars, 2013. p. 159-178.

MASSINI-CAGLIARI, G. Loans and foreign first names as clues to Phonological Identity in Brazilian Portuguese. In: HORNSBY, D. (Org.). Interfaces in language 2. v. 1. Newcastle upon Tyne: Cambridge Scholars, 2011a. p. 53-67.

. Adaptação fonológica de nomes próprios de origem estrangeira: comparação entre Português Arcaico e Português Brasileiro. Estudos Linguísticos, São Paulo, 40 (2), p. 795-807, mai./ago. 2011b.

Discutindo questões de identidade a partir da (não) adaptação fonológica de nomes próprios de origem estrangeira no Brasil. In: NEVES, M. H. de M. As interfaces da gramática. Araraquara: FCL-UNESP Laboratório Editorial; São Paulo: Cultura Acadêmica, 2010. (Série Trilhas Linguísticas 18). p. 73-90.

MENDONÇA, M. R. de S. Um gênero quadro a quadro: a história em quadrinhos. In: DIONISIO, A. P.; MACHADO, A. R.; BEZERRA, M. A. (Orgs.). Gêneros textuais \& ensino. Rio de Janeiro: Lucerna, 2002. p. 194-207. 
PASSARELLI, L. G. Os quadrinhos na educação lingüística: história, teoria e prática. In: BASTOS, N. B. (Org.). Língua Portuguesa em calidoscópio. São Paulo: EDUC, 2004. p. 47-59.

PASSOS, L. A.; VIEIRA, M. S. de P. A contribuição do gênero história em quadrinhos para o desenvolvimento da leitura. Anais do IV Simpósio Internacional de Ensino de Língua Portuguesa. 2014. Disponível em: < http://www.ileel.ufu.br/anaisdosielp/wpcontent/uploads/2014/11/1690.pdf $>$. Acesso em: 08 mar. 2018.

PRADO, N. C. A influência da língua inglesa na formação de nomes comerciais: questões de identidade linguística e cultural. 2014. 343 f. Tese (Doutorado em Linguística e Língua Portuguesa) - Faculdade de Ciências e Letras, Universidade Estadual Paulista "Júlio de Mesquita Filho", Araraquara, 2014.

RAMOS, P. A leitura dos quadrinhos. São Paulo: Contexto, 2012.

. Histórias em quadrinhos: gênero ou hipergênero. Estudos Lingüísticos, v. XXXVIII, p. 355-367, 2009.

. Histórias em quadrinhos: um novo objeto de estudos. Estudos Lingüísticos, v. XXXV, p. 1574-1583, 2006.

Piadas e tiras em quadrinhos: a oralidade presente nos textos de humor.

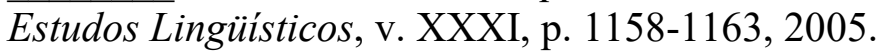

SANDMANN, A. J. Morfologia Lexical. São Paulo: Contexto, 1997.

SILVA, R. L. A contribuição das histórias em quadrinhos de super-heróis para a formação de leitores críticos. Revista Anagrama: revista científica interdisciplinar de graduação. 2011. Disponível em:

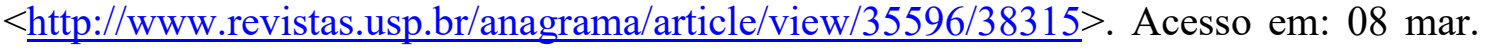
2018.

SILVÉRIO, L. B. R.; REZENDE, L. A. de. O valor pedagógico das histórias em quadrinhos no percurso do docente de língua portuguesa. Anais da I Jornada de Didática - O ensino como foco e do I Fórum de professores do estado do Paraná. 2014. Disponível em: $<\underline{\text { http://www.uel.br/eventos/jornadadidatica/pages/arquivos/O\%20VALOR\%20PEDAG }}$ OGICO $\% 20$ DAS $\% 20$ HISTORIAS\%20EM\%20QUADRINHOS.pdf $>$. Acesso em: 08 mar. 2018.

SOUZA, S. M. L. S. de. Antropônimos de origem inglesa: adaptações ortográficas e fonético-fonológicas realizadas por falantes do português brasileiro de São Luís-MA. 2011. 248 f. Tese (Doutorado em Linguística e Língua Portuguesa) - Faculdade de Ciências e Letras, Universidade Estadual Paulista "Júlio de Mesquita Filho", Araraquara, 2011.

VERGUEIRO, W. A pesquisa em quadrinhos no Brasil: a contribuição da universidade. In: LUYTEN, S. B. (Org.). Cultura pop japonesa. São Paulo: Hedra, 2005. p. 15-26.

Recebido em: 20/08/2017

Aprovado em: 14/03/2018 